\title{
Preventive chemotherapy for schistosomiasis and soil-transmitted helminthiasis by cotreatment with praziquantel and albendazole
}

Clin. Invest. (2014) 4(2), 163-176

In disease-endemic areas, preventive chemotherapy with two orally administered anthelminthic drugs, praziquantel and albendazole, forms the foundation of control of schistosomiasis and soil-transmitted helminthiasis. Where diseases overlap, these two drugs are typically co-administered simultaneously, although albendazole is often interchangeable with mebendazole. With a supportive pharmaceutical industry that donates drugs and a strong international partnership that mobilizes donor funds for drug delivery, scale-up of treatment in school-aged children has expanded significantly in line with the WHO 2012-2020 strategic plan. Other high-risk groups, such as pre-school-aged children, are now benefiting from deworming campaigns conducted alongside other childhood interventions, such as vaccination, less so, however, for schistosomiasis as infections in this age class are not being treated. Looking to the future, maintaining an effective drug distribution and reporting system that regularly checks anthelminthic performance alongside documenting improvements in child health are essential for the long-term success of preventive chemotherapy with praziquantel and albendazole.

Keywords: ascariasis • deworming • hookworm • intestinal schistosomiasis - trichuriasis • urogenital schistosomiasis

Background \& introducing preventive chemotherapy

With the fruition of international advocacy to highlight the importance of diseases within neglected people of the world, a total of 17 neglected tropical diseases (NTDs) are now recognized. These are grouped into two major categories, each with clear intervention strategies as developed by the WHO. Collectively NTDs account for a significant global burden of disease as measured by the disability-adjusted-life-year that was recently revised to include outcomes directly attributable to them, namely, NTD-related anemia [1]. Whilst not directly equivalent with HIV/AIDS, tuberculosis and malaria, the so-called 'big three', NTDs are perhaps of greatest renown for impairing childhood development, inducing disfigurement and social stigmatization [2]. Moreover they perpetuate the cycle of poverty for both individuals and communities afflicted by them. In sharp contrast to control of the 'big three' for which interventions at the individual level are typically considered expensive, interventions against several NTDs caused by nematodes, namely, lymphatic filariasis (elephantiasis), onchocerciasis (river blindness), soil-transmitted helminthiasis (STH), or trematodes, namely schistosomiasis (Bilharzia), are eminently affordable [3]. Indeed, it makes sound economic sense at the public health level, with rapid-impact health packages that attempt to work in an integrated manner [4]. Furthermore control of schistosomiasis and
J Russell Stothard*1, Amaya Bustinduy $^{1,2}$ \& Antonio Montresor ${ }^{3}$

${ }^{1}$ Parasitology Department, Liverpool School of Tropical Medicine, Pembroke Place, Liverpool, L3 5QA, UK

2Paediatric Department, Paediatric Infectious Diseases, St Thomas' Hospital, Lambeth Place Road, London, SE1 7EH, UK

${ }^{3}$ Department of Neglected Tropical Diseases, World Health Organization, Geneva, Switzerland

*Author for correspondence:

E-mail:jrstoth@liverpool.ac.uk
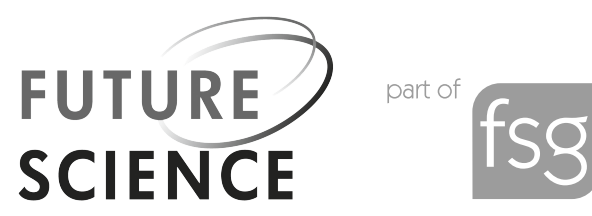
STH is also thought to impart benefits on the prognosis of those with HIV by retarding progression onto AIDS (see below) [5].

A uniting feature of control of these NTDs is promotion of better and regular access to existing anthelminthic treatment(s), alternatively known as dewormers, which is the foundation for abating present and future morbidity [2]. This works by either attempting to eliminate parasite transmission, for example lymphatic filariasis, or to depress within-host worm burdens on a regular basis, for example schistosomiasis and STH [6,7]. Thus the terminology of preventive chemotherapy for human helminthiasis was coined and was later endorsed by World Health Assembly resolutions beginning with WHA54.19 in 2001 encouraging scale-up to reach stipulated drug coverage targets [8,9]. Just over 10 years later, the 2012 London Declaration on Neglected Tropical Diseases provided a further advocacy platform where a number of leading international donors and agencies formally agreed to sustain, expand and extend drug access programs in line with evolving preventive chemotherapy (PC) strategies $[2,10]$.

Moreover, this declaration ensured the necessary supply of drugs gratis and other interventions to help control schistosomiasis, STH, onchocerciasis and lymphatic filariasis by 2020 as envisaged within the 2012-2020 WHO Strategic Plan [7]. Thus with a simple drug armamentarium consisting of ivermectin (IVM), diethylcarbamazine citrate (DEC), albendazole (ALB), mebendazole (MEB) and praziquantel (PZQ), a tool ready method for large-scale control by PC with integrated co-delivery of treatments was feasible [8,11]. A list of commitments secured at this meeting can be found at [101].

Thus with a supportive pharmaceutical industry that donates drugs and a strong international partnership of advocates that mobilizes donor funds for drug delivery, a strong international treatment platform fostered the scale-up and delivery of treatments to afflicted communities throughout the world, see Figure 1. Whilst PC is the foundation for control of schistosomiasis and STH [10], other interventions that encourage inter-sectoral collaboration should not be eclipsed [2]. Those that enhance access to better sanitation, safe water provision, behavioral change and control of intermediate hosts (schistosomiasis), are each highlighted in the WHO 2012-2020 strategic plan and known to synergize and bolster PC measures [7,12]. For schistosomiasis and STH this is particularly pertinent for the drugs used in PC do not safeguard against re-infection, so reparasitism after deworming can follow quickly should local conditions be conducive. Thus PC can be seen as a long-term commitment to the provision of shortterm deworming medications until sufficient evidence is accrued for stopping decisions, namely cessation of periodic treatment $(s)$, to be taken.

\section{- Schistosomiasis \& STH}

Schistosomiasis and STH are caused by several different species of trematode and nematode worm respectively that have some commonalities in the mode of transmission and mechanism of environmental contamination [13]. Table 1 summarizes some of the more pertinent features of the epidemiology of these parasites, noting that there are two forms of schistosomiasis, urogenital and intestinal, which can occur alone or in combination with any or all of the listed STHs.

Urogenital schistosomiasis is now the preferred terminology rather than urinary schistosomiasis as used previously. This is in recognition of the detrimental impact of the disease on genitalia and future reproductive health, particularly in girls with female genital schistosomiasis (FGS) [14,15]. Recent research on FGS has revealed the strong link with HIV and looking to the future, control of FGS should feature within HIV campaigns equally as much as control of sexually transmitted infections [16]. The latter diseases are more well-known risk factors in HIV public health campaigns. In terms of NTD biology, the foremost difference between trematodes and nematodes is that the schistosomes require an intermediate snail host to complete their lifecycle whereas gastrointestinal nematodes do not [17]. All, however, flourish by poor sanitation, whereby parasite eggs reach the environment in urine (Schistosoma haematobium) or feces (Schistosoma mansoni, Ascaris lumbricoides, Trichuris trichiura, hookworm) from infected hosts. Recent research has also highlighted the zoonotic potential of several of these worms highlighting that 'one health' strategies of control should be considered alongside PC [7].

More broadly, where there is poor sanitation and hygiene, the global numbers of people infected or at risk of infection with schistosomiasis and STH are astounding. In 2011 for example, it was estimated that worldwide 112 million school-aged children (SAC) lived in high-risk areas for schistosomiasis, while 875 million children lived in high-risk areas for STH, with 30\% of these being children $<5$ years of age, that is, the preschool-aged children (preSAC) [18]. There are as yet no precise global estimates of the numbers of children presently infected with two or more of these parasites, yet these unknown proportions likely exacerbate the known detrimental effects of worm infection on quality of life, childhood growth and cognitive development $[19,20]$; another shortcoming of the disability-adjustedlife-year is quantification of these cumulative effects. Indeed, such risk maps are at best underestimates of the true distribution of infection owing to the shortcoming of present diagnostic methods used to quantify the prevalence and intensity of infections across this vast geographical landscape, these ambiguities likely 


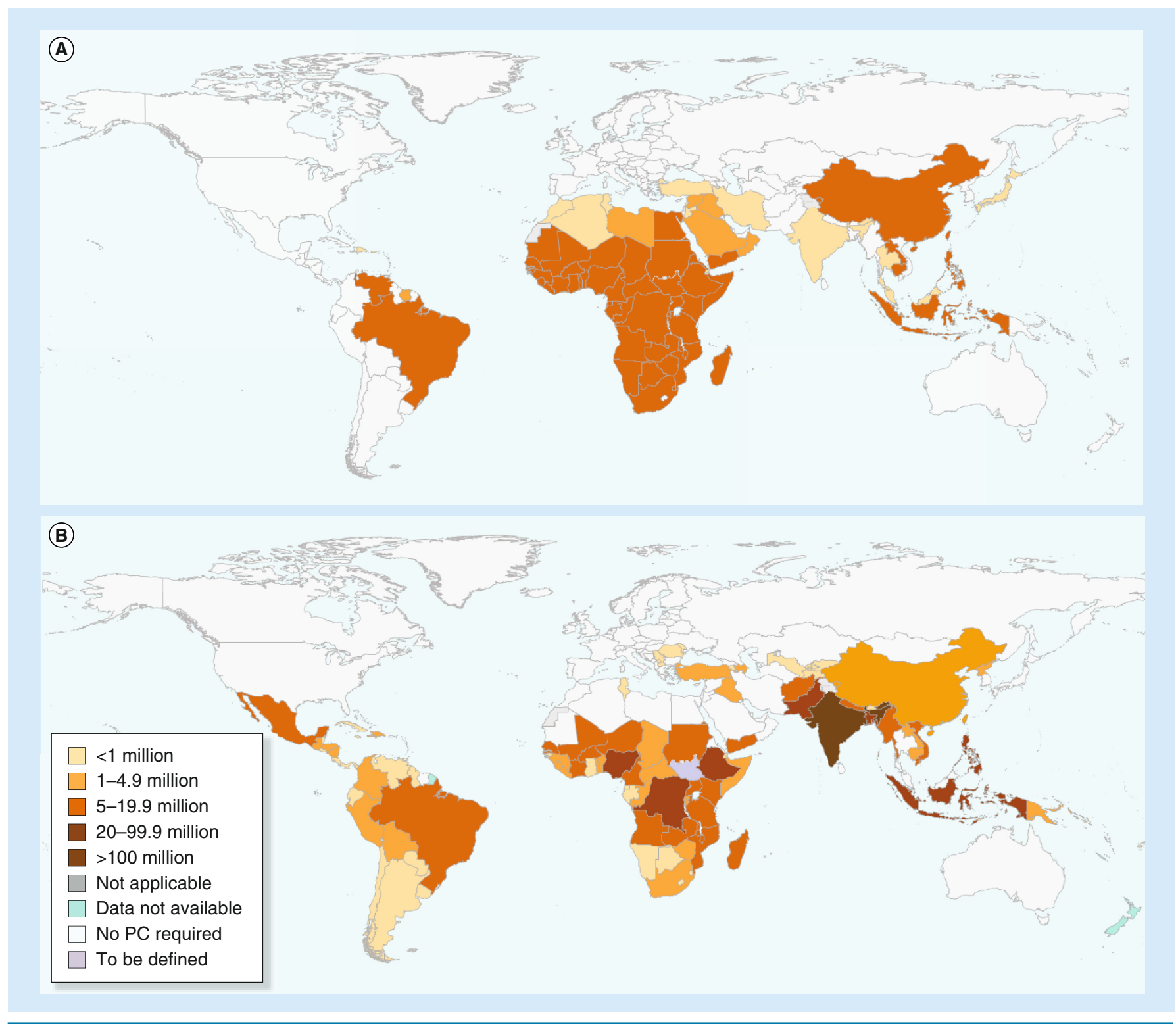

Figure 1. Global distribution of (A) schistosomiasis and (B) soil-transmitted helminthiasis with estimated needs for preventive chemotherapy.

PC: Preventive chemotherapy.

Reproduced with permission from [105] @ WHO (2013).

confounded the studies within the recent Cochrane Review on school-based deworming and educational performance [21-23] and engendered debate [24].

\section{- Combined diagnosis \& foundation for cotreatment}

Whilst there are a variety of diagnostic tools available to detect active infections of schistosomiasis and STH, spanning antigen-antibody-DNA methodologies, the most pragmatic methods, as advocated by the WHO, include the use of classical parasitological methods undertaken upon a sample of the local children $[25,26]$.
Here, a trained microscopist detects parasite eggs in excreta by simple filtration and smear methodologies. Preparations from stool or urine are then visualized by compound microscopy at $\times 100$ or $\times 400$ magnification; egg tallies of encountered helminths are recorded then expressed as an eggs per gram (epg) of feces or per $10 \mathrm{ml}$ of urine. Such enumerations are with the firm intentions to compare the severity of disease(s) from location to location. In so doing, rational decisions for the prioritization of control can be taken.

Diagnostic exceptions include the use of redurine questionnaires for the detection of urogenital 
Table 1. Selected epidemiological features and anthelminthic drugs for control of schistosomiasis and soil-transmitted helminthiasis.

\begin{tabular}{|c|c|c|c|c|}
\hline Subtype & Species & Mode of parasite entry and exit & Treatment by MDA & 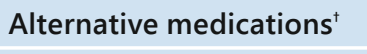 \\
\hline \multicolumn{5}{|c|}{ Schistosomiasis } \\
\hline Urogenital & $\begin{array}{l}\text { Schistosoma } \\
\text { haematobium }\end{array}$ & $\begin{array}{l}\text { Water-borne, larval stages } \\
\text { (cercariae) emerging from } \\
\text { infected snails penetrate intact } \\
\text { skin upon direct contact }\end{array}$ & $\begin{array}{l}\text { PZQ (in } 600-\mathrm{mg} \text { tablets) donated } \\
\text { by Merck-KGaA is effective against } \\
\text { adult worms but not immature } \\
\text { worms }\end{array}$ & $\begin{array}{l}\text { Metrifonate }{ }^{\ddagger} \text { (in } 100-\mathrm{mg} \\
\text { tablets) is active against } \\
\text { Schistosoma haematobium } \\
\text { at } 7.5 \mathrm{mg} / \mathrm{kg} \text { dosing } \\
\text { on three occasions at } \\
\text { intervals of } 2 \text { weeks }\end{array}$ \\
\hline Intestinal $\left.\right|^{\S}$ & $\begin{array}{l}\text { Schistosoma } \\
\text { mansoni } \\
\text { Schistosoma } \\
\text { japonicum }\end{array}$ & $\begin{array}{l}\text { Adult worm pairs reside in the } \\
\text { blood vasculature and release } \\
\text { copious amounts of eggs in } \\
\text { urine or feces }\end{array}$ & $\begin{array}{l}\text { Single dose of either } 40 \text { or } \\
60 \mathrm{mg} / \mathrm{kg} \text { by bodyweight as } \\
\text { estimated by weighing scales or } \\
\text { height pole } \\
\text { Licensed for children }>4 \text { years old }\end{array}$ & $\begin{array}{l}\text { Oxamniquine (in } 250-\mathrm{mg} \\
\text { capsules) is active against } \\
\text { S. mansoni at } 30 \mathrm{mg} / \mathrm{kg} \text { in } \\
\text { two divided doses }\end{array}$ \\
\hline \multicolumn{5}{|c|}{ Soil-transmitted helminthiasis" } \\
\hline Ascariasis & $\begin{array}{l}\text { Ascaris } \\
\text { lumbricoides }\end{array}$ & $\begin{array}{l}\text { Terrestrial, ingestion of } \\
\text { parasite eggs from fecal-oral } \\
\text { contamination }\end{array}$ & $\begin{array}{l}\mathrm{ALB}^{++} \text {(in } 400 \mathrm{mg} \text { tablets) donated } \\
\text { by GlaxoSmithKline single dose } \\
\text { treatment for children aged } \\
>2 \text { years of age, with a half tablet } \\
\text { for children aged between } 1 \text { and } \\
2 \text { years }\end{array}$ & $\begin{array}{l}\text { Levamisole (in } 50 \mathrm{mg} \\
\text { tablets) single-dose } \\
\text { treatment at } 2.5 \mathrm{mg} / \mathrm{kg}\end{array}$ \\
\hline Trichuriasis & $\begin{array}{l}\text { Trichuris } \\
\text { Trichiura }\end{array}$ & $\begin{array}{l}\text { Adult worms reside within the } \\
\text { lumen of the bowel releasing } \\
\text { eggs in feces }\end{array}$ & - & $\begin{array}{l}\text { Piperazine (in } 500 \mathrm{mg} \\
\text { tablets) in single dose at } \\
75 \mathrm{mg} / \mathrm{kg} \text { to a maximum } \\
\text { of } 3.5 \mathrm{~g} \text { in adults and } \\
2.5 \mathrm{~g} \text { in children between } \\
2-12 \text { years of age }\end{array}$ \\
\hline Hookworm & $\begin{array}{l}\text { Necator } \\
\text { americanus } \\
\text { Ancylostoma } \\
\text { duodenale }\end{array}$ & $\begin{array}{l}\text { Terrestrial, larval stages (L3) } \\
\text { penetrate intact skin }\end{array}$ & $\begin{array}{l}\text { MEB (in } 500 \text { mg tablets) donated } \\
\text { by Johnson \& Johnson, single dose } \\
\text { treatment for children }>1 \text { year old }\end{array}$ & $\begin{array}{l}\text { Pyrantel pamoate (in } \\
250 \mathrm{mg} \text { tablets) in a single } \\
\text { dose of } 10 \mathrm{mg} / \mathrm{kg}\end{array}$ \\
\hline $\begin{array}{l}\text { +Used in case-by } \\
\text { "No longer com } \\
\text { "There are three } \\
\text { "Sporadic produ } \\
\text { "Omitting Stron } \\
\text { "Broad spectrur } \\
\text { ALB: Albendazo }\end{array}$ & $\begin{array}{l}\text { settings rather than } \\
\text { ally produced. } \\
\text { species that cause } \\
\text { in Brazil alone. } \\
\text { les stercoralis. } \\
\text { less effective agains } \\
\text { A: Mass drug admir }\end{array}$ & $\begin{array}{l}\text { testinal disease: Schistosoma intercalatum, S } \\
\text { trichuriasis and hookworm. } \\
\text { istration: MEB: Mebendazole: PZO: Praziquan }\end{array}$ & chistosoma guineensis, Schistosoma mekongi & ut are of less global importance. \\
\hline
\end{tabular}

schistosomiasis, where by interviewers (typically teachers) pose a suite of questions to the child (interviewee) [11]. Since visible blood in urine (macrohematuria) is a pathognomonic sign of active infection, especially in boys, this is an accepted method to infer local prevalence of disease (Table 2). Although red-urine questionnaires are not particularly useful in mapping disease distributions where there has been previous distribution of $\mathrm{PZQ}$, recourse to chemical reagent strips that detect microhematuria is more insightful.

For parasitic ova found in the feces, the single KatoKatz thick smear is the field-operational 'gold standard'. In essence, $41.7 \mathrm{mg}$ of stool is partially purified by size selection through a metal or nylon sieve of $200-300 \mu \mathrm{m}$ pore size, then smeared on a glass slide and inspected at $\times 100$ magnification [11]. This amount of stool is typically sufficient to detect eggs shed from adult female worms found in or around the intestine. As S. haematobium resides in the vasculature surrounding the vesicle plexus, in order to detect of urogenital schistosomiasis $10 \mathrm{ml}$ of urine, as collected mid-morning, is filtered by plastic syringe through a nylon membrane of $10-30 \mu \mathrm{m}$ pore size. This filter retains schistosome eggs, and is then inspected at $\times 100$ magnification [11]. Whilst effective for use in this field, there are several short-comings of these methods, which typically center around the low diagnostic sensitivity of methods when infections are perceived as 'light', namely when there are only a 
handful (or fewer) eggs being shed by the host. To raise sensitivity, multiple stool and urine specimens taken over consecutive days may increase sensitivity but this incurs increased costs of logistics and staff time, which are often the limiting factors when numerous locations are to be visited for disease surveillance.

Estimating the prevalence of disease locally is important as there are thresholds in prevalence, as recommended by WHO [6,7], that trigger different treatment strategies (Table 2). These are based on data from surveys in which a single specimen is taken and takes into consideration the sensitivity of the diagnostic method used, for example it is recognized that when a $30 \%$ prevalence of STH is estimated in a population with a single Kato-Katz, the 'real' STH prevalence estimated with a more sensitive method would probably correspond to $40-45 \%$; the WHO treatment strategies take into consideration these diagnostic biases. Across a disease landscape, the diagnostic coverage by location and performance of these methods is a working compromise between available resources and specific surveillance needs $[27,28]$. Care needs to be taken on interpretation of 'risk maps' that are derived from such information that is inherently confounded by the lack of diagnostic precision and insufficient density of sampled locations [29].

\section{- Unavoidable operational compromises}

At a programmatic level, there are two major uses of these diagnostic tools [4]. First is for general detection of disease within communities (rather than individuals per se) to help build a 'working' local distribution map attempting to record the endemicity of each disease. Second these methods are used to assess the efficacy of deworming treatment(s), where programs seek to measure either short-term impact, 24-28 days after treatment, namely drug pharmacodynamics [30], or long-term impact over

\begin{tabular}{|c|c|c|c|}
\hline Category & Baseline prevalence among SAC & \multicolumn{2}{|c|}{ Action to be taken with PZQ or ALB/MEB ${ }^{+}$} \\
\hline \multicolumn{4}{|c|}{ High-risk community } \\
\hline Schistosomiasis & $\begin{array}{l}\geq 50 \% \text { by parasitological methods }{ }^{\ddagger} \\
\text { (intestinal and urogenital } \\
\text { schistosomiasis); } \\
\text { Or } \geq 30 \% \text { by questionnaire for history } \\
\text { of haematuria }\end{array}$ & $\begin{array}{l}\text { Treat all SAC } \\
\text { (enrolled and not enrolled) } \\
\text { once a year }\end{array}$ & $\begin{array}{l}\text { Also treat adults considered to be at } \\
\text { risk (from special groups }{ }^{\S} \text { to entire } \\
\text { communities living in endemic areas) }\end{array}$ \\
\hline STH & $\begin{array}{l}50 \% \text { by parasitological inspection } \\
\text { methods of fecal material }\end{array}$ & Treat all SAC twice a year & $\begin{array}{l}\text { Treat preSAC and women of child-bearing } \\
\text { age twice a year }\end{array}$ \\
\hline \multicolumn{4}{|c|}{ Moderate-risk community } \\
\hline Schistosomiasis & $\begin{array}{l}\geq 10 \% \text { but }<50 \% \text { by parasitological } \\
\text { methods } \\
\text { (intestinal and urogenital } \\
\text { schistosomiasis); } \\
\text { Or }<30 \% \text { by questionnaire for history } \\
\text { of haematuria }\end{array}$ & $\begin{array}{l}\text { Treat all SAC (enrolled and } \\
\text { not enrolled) once every } \\
2 \text { years }\end{array}$ & $\begin{array}{l}\text { Also treat adults considered to be at risk } \\
\text { (special groups }{ }^{\S} \text { only) }\end{array}$ \\
\hline STH & $\begin{array}{l}\geq 20 \% \text { by }<50 \% \text { by parasitological } \\
\text { inspection methods of fecal material }\end{array}$ & Treat all SAC once a year & $\begin{array}{l}\text { Treat preSAC and women of child-bearing } \\
\text { age once a year }\end{array}$ \\
\hline \multicolumn{4}{|c|}{ Low-risk community } \\
\hline Schistosomiasis & $\begin{array}{l}<10 \% \text { by parasitological methods } \\
\text { (intestinal and urogenital } \\
\text { schistosomiasis) }\end{array}$ & $\begin{array}{l}\text { Treat all school-age } \\
\text { children (enrolled and not } \\
\text { enrolled) twice during their } \\
\text { primary schooling age } \\
\text { (e.g., once on entry and } \\
\text { once on exit) }\end{array}$ & $\begin{array}{l}\text { PZQ should be available in dispensaries } \\
\text { and clinics for treatment of suspected } \\
\text { cases }\end{array}$ \\
\hline STH & $\begin{array}{l}<20 \% \text { by parasitological inspection } \\
\text { methods of fecal material }\end{array}$ & $\begin{array}{l}\text { Case-by-case treatment } \\
\text { of SAC }\end{array}$ & $\begin{array}{l}\text { Case-by-case treatment of preSAC and } \\
\text { women of child bearing age }\end{array}$ \\
\hline \multicolumn{4}{|c|}{$\begin{array}{l}\text { "Equivalent to: High-risk community: All school-age children and adults require preventive chemotherapy annually; Moderate-risk community: } 50 \% \text { of school-age } \\
\text { children and } 20 \% \text { of adults require preventive chemotherapy annually; Low-risk community: } 33 \% \text { of school-age children require preventive chemotherapy annually. } \\
\text { "For urogenital schistosomiasis, detection of hematuria by chemical reagent strips gives results equivalent to those determined by urine filtration. } \\
\text { ¡Special groups: Pregnant and lactating women; groups with occupations involving contact with infested water such as fishermen, farmers, irrigation workers or women } \\
\text { in their domestic tasks, to entire communities living in endemic areas. } \\
\text { ALB: Albendazole; MEB: Mebendazole; PZQ: Praziquantel; SAC: School-aged children; STH: Soil-transmitted helminthiasis. }\end{array}$} \\
\hline
\end{tabular}


more extended timeframes, years and longer, between treatments that typically precede consecutive PC treatment cycles [31]. The former is typically expressed in terms of cure rate (CR) and egg reduction rate (ERR) and has been used widely in the literature to monitor the performance of PZQ and ALB. The latter is reported as changes in disease prevalence and intensity of infections in comparison to that prior to intervention $[32,33]$.

On the whole, short-term drug performance of PZQ and ALB is typically good with parasitological CRs often in excess of $75 \%$ [34]. However, there can be exceptions, for example low cure rates $<50 \%$ in Senegal, preSAC children with intestinal schistosomiasis [35] or STH [36], respectively. Following recent discussions in WHO-Geneva and investigations of the dynamics of these metrics, it is now considered that ERR is thought to be a better estimate of drug performance, which typically is approximately $>85 \%$ $[37,38]$. A central difficulty in measuring the short-term impact of anthelminthic with CR is in the nature of worm egg excretion itself and that fecal epgs are often over-dispersed across an endemic community, namely, some individuals have inordinately higher epgs than others, thereby 'skewing' leads to an underestimate of cure [22].

For example, whilst there may be reductions of several thousand shed parasite eggs to only a handful, these non-negative values represent 'treatment failures', when CR is used, ERR on the other hand is not influenced as much by the overdispersed distribution of eggs in the population, especially if a geometric mean epg is used $[37,38]$. A central tenet of PC is to reduce worm burdens, and it is perhaps unrealistic to expect a complete cure if sampled children range with worm burdens ranging in five or more orders of magnitude, namely, 10, 100, $1000,10000+$. Since drugs are given out as single dose and not 'dose-ranged' or 'weighted' towards increasing parasite densities, thus fixed dosing at the heavier intensity of infections is likely sub-curative if drug uptake levels are initially swamped by masses of worms. The merits between using actual egg intensities or threshold classifications has been debated elsewhere, but for schistosomiasis, where the disease is typically resultant from the accumulation of eggs trapped in tissues [17], it should be noted that any significant reductions in egg production can be considered a successful outcome of PZQ treatment. Changes in disease prevalence after treatment are often difficult to predict and are determined empirically. Recent studies have shown that reinfection dynamics are often place-specific owing to the inherent heterogeneity in a myriad of causal factors that vary from location-to-location, for example levels of sanitation and environmental contamination amongst others [11].

\section{- Rationale drug delivery across a disease landscape}

The fundamental raison d'etre for mapping is to set and to guide on-the-ground intervention zones [4,11]. There are informal WHO documents that attempt to streamline this surveillance task in terms of number of locations to be sampled, typically primary schools (that act as convenient geographical anchor points) [39,40], and the numbers of children to be screened at each location, usually 60 or less [41]. It is beyond the scope of this review to address the merits of lot quality assurance sampling (LQAS) versus fixed sample sizes for estimation of the local prevalence of disease, however, each method attempts to classify a location as high, moderate and low-risk of disease (Table 2). Aiming to maximize the geographical knowledge of disease endemicity between nonsampled points, namely to bolster field sampling that is logistically challenging, has seen the rise of remotely sensed environmental data with spatial modeling and risk prediction. Although creation of spatially explicit databases is important [102], the accuracy and reliability of predictive disease maps derived from it to guide PC still engenders debate [42]. Foremost, is that although chronic, these diseases are prone to the dynamics of environmental and anthropogenic changes, thus spatial-risk predictions need regular updating and validation to remain informative through time before becoming locally obsolete $[40,41]$.

Nonetheless, evidence-based decisions taken upon the known or likely distribution of schistosomiasis and STH across a countries' landscape is vital to setting and forecasting anthelminthic drug requirements of PZQ and ALB or MEB [6,43]. This is at the onset of a national control program implementing $\mathrm{PC}$ as part of its strategic plan and temporal road map of possible interventions to be taken through time [44]. Here, it should also be noted that surveillance of schistosomiasis and STH does not operate alone and for it is, or should be, incorporated within the geographical landscape for surveillance of other NTDs, for example for lymphatic filariasis and onchoceriasis $[29,45]$. This is because for PC treatment associated with the latter two diseases, impacts upon STH, for IVM and ALB taken individually or combined, has tangible impact upon each nematode species [46]. Indeed, the algorithm for PC is illustrated in Figure 2, in which umbrella treatment decisions for lymphatic filariasis and onchocerciasis are part of the treatment decisions tree.

These PC treatment algorithms mesh with the prevalence threshold guidelines of Table 2, such that in high prevalence areas of schistosomiasis, STH and lymphatic filariasis, a SAC can expect to receive two biannual doses of ALB, each co-administered with IVM (one for lymphatic filariasis treatment) or PZQ (one with schistosomiasis cotreatment) spaced apart by approximately 6 months. The exact timing of these treatments during 
the calendar year; however, can vary due to logistical constraints that may delay the drug delivery operations. Indeed, it can be challenging for national control program managers to work in a harmonized way [47] when there have been global shortages in drugs and difficulties in international shipping [48]. Foremost for PZQ, for example, the present demand for the drug currently outstrips production five-fold. This is thought to ease in forthcoming years as the MerckKGaA annual donation of 250 million tablets is realized.

\section{- PreSAC have equitable access to ALB but not PZQ}

A glaring exception in this cotreatment algorithm is the drug delivery situation in preSAC. Until 2002, WHO did not recommend largescale treatment interventions with ALB or MEB to preSAC under the age of 24 months, yet infections in this age class were previously known, in particular for ascariasis and trichuriasis [49]. These infections can be acquired soon after birth being linked by the correlated epidemiology of mother and child. An expert meeting was held in April 2002 at WHO-Geneva to discuss access of preSAC to anthelminthics; at the same time discussions also centered on the use of PZQ in pregnant women, which was then contraindicated in drug licensing [6]. Upon consideration of all available evidence the meeting concluded that preSAC children should be provided with ALB or MEB on a regular basis, reasons for this are discussed below [11]. Today treatment of preSAC with ALB or MEB has been a much under acknowledged success of PC campaigns. In 2009 for example, over 50 countries reported data with a total of 109.7 million preSAC treated during immunization campaigns, vitamin A supplementation, child-health days and elimination campaigns for lymphatic filariasis. Notably in Africa, of the 42 countries requiring PC, 25 reported data in 2009 with more than 50 million preSAC children corresponding to a regional treatment coverage of $>46 \%$ [6].

The situation for treatment of preSAC with schistosomiasis is less than satisfactory and mirrors the situation found in STH treatment just over a decade ago. In high transmission areas it is clear that preSAC can have active schistosomiasis acquired by passive water contact, namely in domestic bathing water [50-55]. Presently children who are patently infected have little or no access to PZQ and this was discussed at length again at WHO-Geneva in September 2010. After reviewing new epidemiological information it was acknowledged that preSAC were a high risk group, particularly vulnerable to infection and that broken and (or) crushed tablets of PZQ could be used for treatment on a case-by-case basis [56]. Large-scale PC campaigns with PZQ in this age class were considered a little premature until a suitable pediatric formulation of PZQ was produced. With the formation of a new public-private-partnership, a pharmaceutical consortium has undertaken the task of developing an orally dispersible tablet, with taste masking, which is presently in pre-clinical evaluation [52]. Nonetheless the burden of schistosomiasis in preSAC remains unchecked by PC as such infected children do not have immediate access to PZQ but they are now recognized as a high-risk group in need of further attention [7].

\section{A focus on PZQ \& ALB}

The chemical structure of PZQ is shown in Figure 3A, representing 2-(cyclohexylcarbonyl)-1,2,3,5,7,11bhexahydro-4H-pyrazino[2,1-a] isoquinoline-4-one [57]. Pertinent features of this drug are listed in Table 3 [58] and reviewed by Doenhoff et al. [59]. PZQ is a racemate [60] of dextro and laevo-isomers and marketed as Biltricide $^{\circledR}$ with a drug licensing schedule of oral dosing at either 40 or $60 \mathrm{mg} / \mathrm{kg}$ bodyweight for adults and children over 4 years of age and active against all species 
of schistosome [61-63]. It is perhaps surprising that there are no pharmacokinetic studies in SAC or preSAC with all available information extrapolated from studies in adults $[64,65]$. It is known that intake of food enhances the drug plasma levels two-five-times, and bioavailability between brands of PZQ can differ [66]. Adults with liver disease (i.e., intestinal schistosomiasis) have different levels and duration of PZQ in plasma, presumably due to changes in levels of the cytochrome P450 detoxification system [67]. Plasma levels are also known to change with co-administration of ALB [68], the latter drug and metabolites thereof is known to increase, but the impact of PZQ on ALB levels is much greater than that of the reverse, namely impact of ALB on PZQ [69].

Considered a rather cumbersome oblong tablet of $600 \mathrm{mg}$, scored in half- or quarter-tablet units, the medication remained relatively expensive until off-patent production by generic manufacturers reduced the price to less than US $\$ 0.10$, making national PC campaigns affordable from 2002 with seed financial encouragement by the Bill \& Melinda Gates Foundation, as supported by the Schistosomiasis Control Initiative, UK. After the London Declaration, Merck-KGaA has now committed in its Merck Praziquantel Donation Programme to supply 250 million tablets each year gratis. Whilst an important and generous step, it is not clear how commercial generic producers will respond to this mixed market of donation and retail as the 250 million tablet donation is ring-fenced for SAC.

An important omission is that adults and preSAC are not factored into this donated drug supply. Even so, any donated or purchased drugs will still require aid budgets to support their delivery and reporting of treatment coverage during on-the-ground operations. Whilst major implementation agencies of SCI, UK and Research Triangle Institute, USA with ICOSA see [103] and ENVISION [104] campaigns have secured funds for scale-up, new obstacles to PC arise, such as erosion of adherence to treatment due to concerns of drug-induced side effects, for example emesis, which can discourage the treatment of others [62]. This is a nontrivial matter, as

there are several instances when rural communities have come to reject these well-meaning health interventions, even when carefully planned [70].

The chemical structure of ALB is shown in Figure 3B, representing methyl 5-(propylthio)-2-benzimidazolecarbamate, a benzimidazole similar in structure to MED and thiabendazole. Pertinent features of this drug are listed in Table 3 [58]. As donated by GlaxoSmithKline (Brentford, UK), ALB is manufactured in an orange flavored chewable circular 400-mg tablet. A recent study has further investigated the interactions between PZQ and ALB in adult volunteers [68]. Upon entering the blood the drug is metabolized to albendazole sulfoxide but unmetabolized ALB is directly effective against nematodes in the alimentary tract $[71,72]$. There is evidence that such nematodes, with their own cytochrome P450 enzymes, metabolize ALB to albendazole sulfoxide, indicating that it is probably a combination of these two drug phenomena [58]. The important message is that ALB does not need to enter the bloodstream to be active on intestinal nematodes, whereas its absorption is necessary for treatment of systemic nematodes or cestodes such as Wuchereria bancrofti or Taenia solium, respectively. Benzimidazole metabolism, like PZQ, depends on oxidation by suite of cytochrome P450s in the liver. The action of ALB is known and interferes with the polymerization of $\beta$-tubulin fibers, with some evidence of genetic mutants that have diminished susceptibility to ALB $[73,74]$.

\section{Practicalities on PZQ \& ALB cotreatment}

The onsite requirements for treatment of SAC children for schistosomiasis and STH, such as treatment registers, potable water, have been recently described elsewhere [75,76], with seminal studies on cotreatment by Olds et al. [31]. Key features of treatment-in-action are shown in Figure 4. The safety of cotreatment has been assessed in a variety of papers in different endemic settings but cannot be considered exhaustive in comparison to the scale of operations where millions are treated [77,78]. Transitory side effects are known that resolve within $24 \mathrm{~h}$ dosing to occur but these are not in excess of either<smiles>O=C(C1CCCCC1)N1CC(=O)N2CCc3ccccc3C2C1</smiles>

(A)

Figure 3. Chemical structures for (A) praziquantel and (B) albendazole.

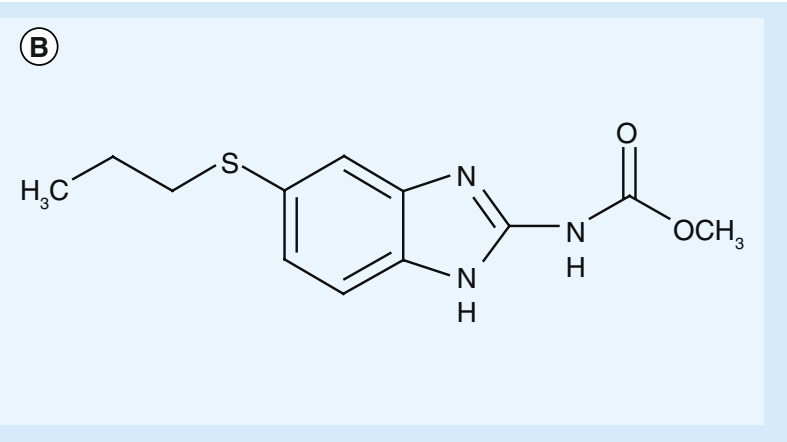

(B) 
Table 3. Essential information on praziquantel and albendazole.

\begin{tabular}{|c|c|}
\hline PZQ (CAS: 55268-74-1; MW 312.3) & ALB (CAS: 54965-21-8; NW: 265.34) \\
\hline \multicolumn{2}{|l|}{ Formulation } \\
\hline $\begin{array}{l}\text { Equimolar racement of R-(-)-PZQ (levorotated, } \\
\text { L-PZQ) and S-(+)-PZQ (dextrorotated, D-PZQ). The } \\
\text { S-(+)-PZQ form confers the unusually bitter taste } \\
600-\mathrm{mg} \text { tablets are usually scored into } 150 \mathrm{mg} \text { or } \\
\text { 300-mg tablet divisions } \\
\text { - Approximately } 80 \% \text { of the dose is excreted in the } \\
\text { urine within } 24 \mathrm{~h}\end{array}$ & $\begin{array}{l}\text { Typically in } 400 \text {-mg orange flavored chewable tablets with } 200-m g \text { division } \\
\text { ALB is typically considered a prodrug for it remains inactive until upon } \\
\text { absorption and is then quickly oxidized by extensive first pass metabolism in } \\
\text { the liver to the active metabolite ASOX, which is further metabolized into the } \\
\text { inactive ASON } \\
\text { - Although active in the bowel lumen, it is thought that worms metabolise ALB } \\
\text { into ASOX by their own cytochrome P450s }\end{array}$ \\
\hline \multicolumn{2}{|l|}{ Mode of action and detoxification } \\
\hline $\begin{array}{l}\text { - Absorption is increased substantially with ingestion } \\
\text { of carbohydrate or fatty food items } \\
\text { - R-(-)- praziquantel and first pass metabolite (trans-4- } \\
\text { hydroxypraziquantel, (-)-(R)-4-OHPZQ) active against } \\
\text { adult worm tegument interfering with membrane } \\
\text { bound calcium channels, predominately on male } \\
\text { worms } \\
\text { Metabolic detoxification depends on cytochrome } \\
\text { P450s in particular CYP3A4 }\end{array}$ & $\begin{array}{l}\text { - Absorption is increased substantially with ingestion of carbohydrate or fatty } \\
\text { food items } \\
\text { - ASOX interferes with parasite } \beta \text {-tubulin molecules that leads to loss of } \\
\text { cytoplasmic microtubules, which impairs glucose uptake and leads to } \\
\text { exhaustion and death. Secondary effects likely include inhibition of fumarate } \\
\text { reductase } \\
\text { - Metabolic activation and detoxification depend on cytochrome P450s in } \\
\text { particular CYP1A1 and CYP3A4 }\end{array}$ \\
\hline
\end{tabular}

drug when administered alone [78,79]. Other features of cotreatment worthy of discussion here relate to dosing and warrant some discussion. The key discriminating feature between the two drugs is the weight-height-dose relationship for PZQ and age-dose relationship for ALB in children aged 12-24 months and older, with Figure 5 attempting to encapsulate these divisions. Foremost is that PZQ is administered by bodyweight at the lower standard $40 \mathrm{mg} / \mathrm{kg}$ dosing.

For preSAC it is likely that this $40 \mathrm{mg} / \mathrm{kg}$ is satisfactory in light of recent pharmacodynamic studies undertaken in Uganda in 2012 and 2013 [Bustinduy AL, Waterhouse D, Kabatereine NB, Ward S, Stothard JR. First pharMACOKINETIC PROFILES OF PLASMA LEVELS OF (+/-)PRAZIQUANTEL AND ASSOCIATED PHARMACODYNAMICS IN PRE-SCHOOL CHILDREN: INVESTIGATION DRUG ADMINISTRATION AT 40 OR 60 MG/KG DOSINGS (2014), Manuscript in preparation], which have abated initial concerns that $40 \mathrm{mg} / \mathrm{kg}$ might have been too high following generic extrapolations of adult dosing into the pediatric settings [80]. It should be noted that a single $600 \mathrm{mg}$ oblong tablet is towards the largest range of size that can be safely tolerated in the small mouths of children, so for preSAC the tablet can be crushed or broken into more acceptable sizes and often administered with a flavored drink to mask its bitter taste. This of course may alter its pharmacokinetics but liquid formulations of PZQ have been shown to be nonsuperior to the crushed tablet alternative. Where weight scales are lacking, an extended dosing pole or treatment stick has been developed to administer tablets on the basis of height, since there is a strong biometric relationship with weight $[35,81]$. The smallest possible tablet division is $150 \mathrm{mg}$ owing to existing scoring [82]. Due to this, dosing by age has been explored in younger children in $150 \mathrm{mg}$ increments that might provide an alternative to height-based dosing in children aged 6 months and over, which are typically underneath the 60-cm height threshold [82]. Higher standard dosing of $60 \mathrm{mg} / \mathrm{kg}$ is possible but as of yet there is no height pole developed for this range.

The situation for ALB dosing is much more straightforward. Adults, SAC and the majority of preSAC children receive a single tablet alone. Owing to slight concerns of drug toxicity in the very young child, in children aged between 12 and 24 months a half-tablet is administered and children younger than one year are presently excluded but can be treated on a case-by-case basis contingent upon

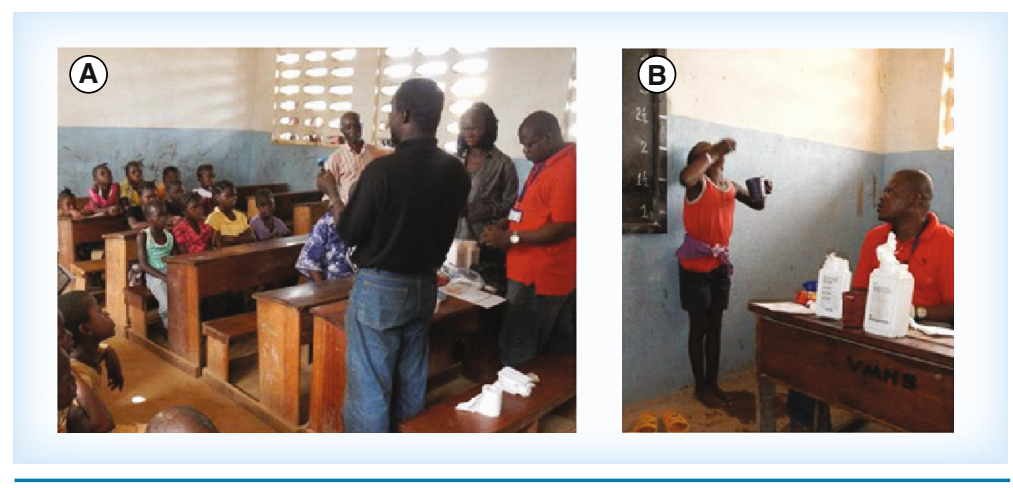

Figure 4. Treatment at the school site in action. (A) Class sensitization of Liberian children to receive treatment and (B) administration of cotreatment. 


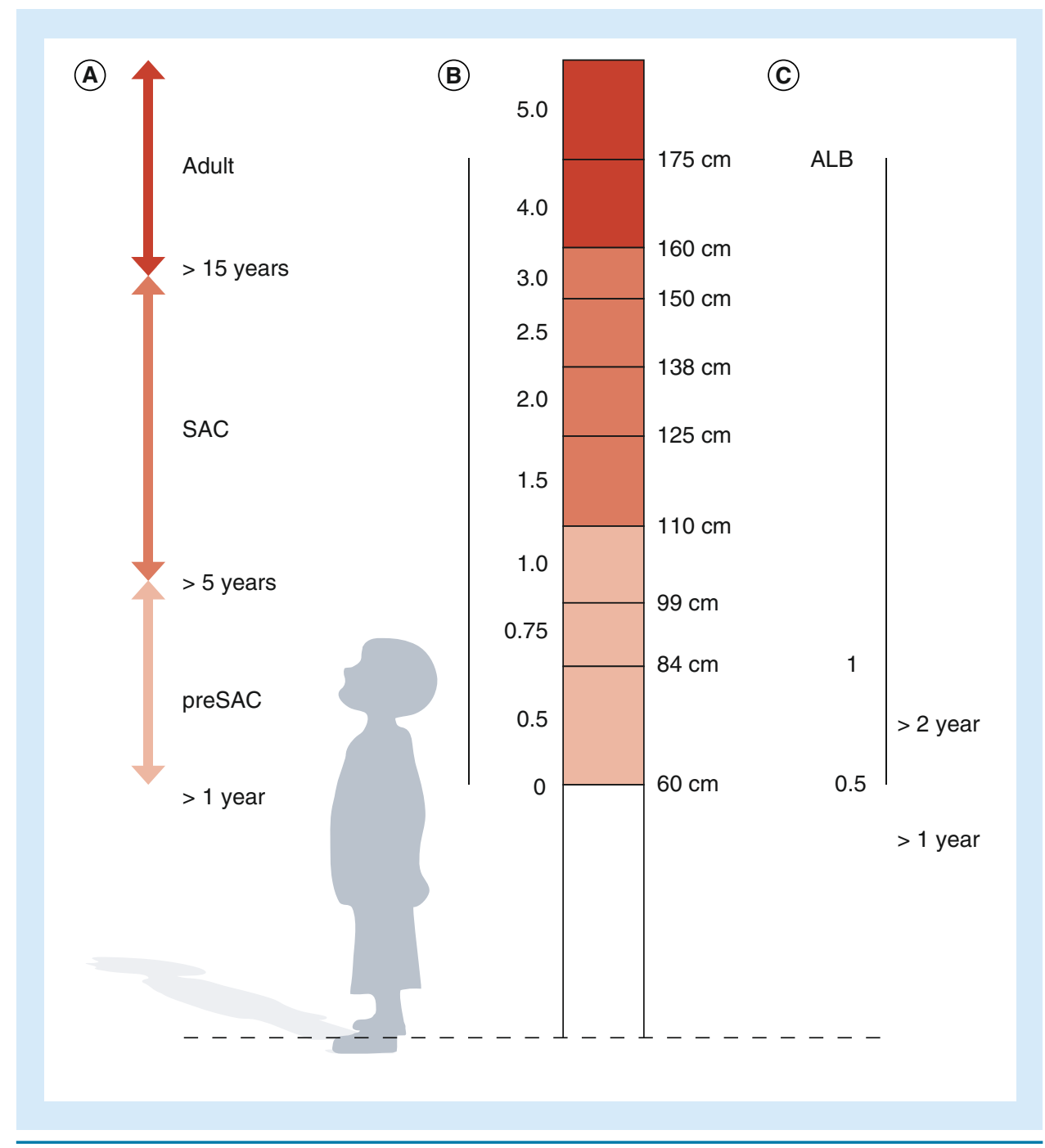

Figure 5. Chart of the relationships between height and age for drug administration. Age range of pre-school-aged children, school-aged children and adults, that (B) corresponds to height thresholds for praziquantel administration and $(C)$ age-range for administration of albendazole.

these locations where treatments are most needed. At the lowest levels, drug administration and coverage is usually recorded by pen and paper in a treatment register booklet [84]. Within a school-based treatment campaign registers are simply grouped by class and often have additional space to record treatments given to children attending school and also to nonenrolled school children who may attend the day of treatment, since PC is to be as inclusive as operationally possible $[7,84]$. It must be remembered that delivery of PC can also take place outside of the school-based infrastructure in community-directed treatment campaigns when community drug distributors are responsible for providing treatment, often in a door-todoor setting $[6,85]$. It is outside the scope of this review to address the relative merits of $\mathrm{PC}$ as delivered by school- or community-based platforms, but it should be remembered that both school-teachers and community drug distributors need some form of basic training to be able to perform administration of treatment well [7]. With scale-up of this work force, often operating on a basis of goodwill, to maintain its integrity through time some consideration of incentive and reward is needed [2]. This can be in the form of simple per diems allowances to compensate for the time 'occupied' in delivering control.

medical discretion. In contrast, MEB (500 mg) can be administered across all preSAC and in so doing simplifies even further the cotreatment regime for STH [6].

\section{- Reporting treatment coverage}

A key feature that needs to be captured in PC is reported treatment coverage and also any side effects and(or) severe adverse events [83]. These are frequently transient resolving within $24 \mathrm{~h}$ after treatment and typically encompass nausea, abdominal discomfort and emesis, however, more severe reactions are known such as anaphylaxis, especially in locations where infection intensities are very high [37]. Fear of such events in a community can lead to reduced adherence with treatment that is particularly unfortunate as it is often in
At a national level, summary statistics are typically presented as reported drug coverage by district then region, as information becomes available and this can be easily inspected country-by-country and year-onyear through the WHO preventive chemotherapy database [83]. The website is regularly updated presenting all reported information from 2006 onwards [105], with interactive maps, summary tabulations and graphical outputs that chart ongoing progress in delivery of PC, see Figure 1. Presently it is, however, difficult to capture precisely the reported treatment coverage of PZQ and ALB combined [6,84], however, this database will be the first point of call in measuring progress towards the 2020 WHO targets where achieving treatment coverage of $75 \%$ is the rally point for future success [2]. 


\section{Future perspective}

It is clear that cotreatment with PZQ and ALB makes sound public health sense when the practicalities of PC are considered in a landscape where schistosomiasis and STH abound. With the scale-up of cotreatment there are opportunities that should not be missed. First is that there will be tangible impacts upon reducing the co-morbidity of other diseases, which should be mindful of the positive impact deworming has upon HIV incidence and progression onto AIDS, with or without antiretroviral therapy [5]. At the same time with scale-up as monitored with the preventive chemotherapy database, vigilance for drug tolerant parasites should increase as there is some evidence that populations of parasites already differ in their susceptibility to these medications. Should this be a major concern? While there are ongoing drug discovery programs for schistosomiasis and STH, it is unlikely that any new anthelminthics will be brought to market within the next decade [86-88], but we believe there to be ample room to explore new dosing requirements that might mitigate any poor performance at either standard lower $40 \mathrm{mg} / \mathrm{kg}$ dosing with PZQ or with single or half-tablet administration of ALB. There is therefore much scope for optimism that existing cotreatment regimes will have a solid and long-term impact upon reducing the burden of disease.

\section{Acknowledgments}

The authors would like to thank M Bockarie for the invitation to contribute to Clinical Investigation on control of neglected tropical diseases, in particular treatment of schistosomiasis and soil-transmitted helminthiasis. The authors are grateful to J Horton for his comments on our manuscript and to $S$ Ward and several colleagues in Merck-Serono who have shared their knowledge of anthelminthic pharmacology with us.

\section{Disclosure}

The opinions of A Montresor do not reflect those of the WHO.

\section{Financial \& competing interests disclosure}

The authors have no relevant affliations or financial involvement with any organization or entity with a financial interest in or financial conflict with the subject matter or materials discussed in the manuscript. This includes employment, consultancies, honoraria, stock ownership or options, expert testimony, grants or patents received or pending, or royalties.

No writing assistance was utilized in the production of this manuscript.

\section{Open Access}

This article is distributed under the terms of the Creative Commons Attribution License 3.0 which permits any use, distribution, and reproduction in any medium, provided the original author(s) and the source are credited. To view a copy of the license, visit http://creativecommons. org/licenses/by/3.0/

\section{Executive summary}

- Cotreatment of children with praziquantel and albendazole is the frontline intervention against schistosomiasis and soil-transmitted helminthiasis, several tens of millions of children are receiving treatment.

- Cotreatment is safe and is orally administered, often by nonmedical personnel, in a WHO endorsed strategy of integrated preventive chemotherapy for neglected tropical diseases.

- Both praziquantel and albendazole are donated gratis by major pharmaceutical agencies, their scale-up in use is in line with WHO predictions for the 2012-2020 period.

- There is scope for future optimization of cotreatment in terms of increased dosing and more frequent periodicity to safeguard drug(s) performance in the longer term.

- Regularly monitoring global needs and routine monitoring of drug efficacy at national levels are essential to sustain drug delivery and ensure an enduring impact.

\section{References}

Papers of special note have been highlighted as:

- of interest

-. of considerable interest

1 Murray CJ, Vos T, Lozano R et al. Disabilityadjusted life years (DAYLs) for 291 diseases and injuries in 21 regions, 1990-2010: A systematic analysis for the global burden of disease study 2010. Lancet 380, 2197-223 (2012).

2 WHO. Sustaining the drive to overcome the global impact of neglected tropical diseases. Second WHO report on Neglected Tropical Diseases. World Health Organization.Geneva, Switzerland (2013).
3 Hotez PJ, Brindley PJ, Bethony JM et al. Helminth infections: the great neglected tropical diseases. J. Clin. Invest. 118, 1311-1321 (2008).

4 Fenwick A, Webster JP, Bosque-Oliva E et al. The schistosomiasis control initiative (SCI): Rationale, development and implementation from 2002-2008. Parasitology. 136, 17191730 (2009).

- Gives an overview of the first progress in scale-up of mass drug administration in the schistosomiasis control initiative supported countries: Uganda, Tanzania, Zambia, Niger, Burkina Faso and Mali.

5 Gerns HL, Sangare LR, Walson JL. Integration of deworming into HIV care and treatment: A neglected opportunity. PLoS Negl. Trop. Dis. 6(7), e1738 (2012).

6 WHO. Soil-Transmitted Helminthiases. Eliminating Soil-Transmitted Helminthiases as a Public Health Probelm in Children. PROGRESS Report 2001-2010 and Strategic Plan 2011-2020. World Health Organisation. Geneva, Switzerland (2012). 
7 WHO. Schistosomiasis. Progress Report 2001-2011 and Strategic Plan 2012-2020. World Health Organisation. Geneva, Switzerland (2013).

8 Gabrielli AF, Montresor A, Chitsulo L et al. Preventive chemotherapy in human helminthiasis: theoretical and operational aspects. Trans. R. Soc. Trop. Med. Hyg. 105, 683-693 (2011).

9 Savioli L, Gabrielli AF, Montresor A et al. Schistosomiasis control in sub-Saharan Africa: 8 years after world health assembly resolution 54.19. Parasitology 136, 1677-1681 (2009).

10 Montresor A, Gabrielli AF, Chitsulo L et al. Preventive chemotherapy and the fight against neglected tropical diseases. Expert Rev. Anti. Infect. Ther. 10, 237-242 (2012).

11 WHO. Helminth control in school-age children. 2nd edition. WHO Press, Geneva, Switzerland (2011).

12 Boatin BA, Basanez M-G, Prichard RK et al. A research agenda for helminth diseases of humans: Towards control and elimination. PLoS Negl. Trop. Dis. 6, (2012).

13 Stothard JR, Chitsulo L, Kristensen TK et al. Control of schistosomiasis in sub-Saharan Africa: progress made, new opportunities and remaining challenges. Parasitology 136 , 1665-1675 (2009).

14 Kjetland EF, Leutscher PD, Ndhlovu PD. A review of female genital schistosomiasis. Trends Parasitol. 28, 58-65 (2012).

15 Kjetland EF, Ndhlovu PD, Gomo E et al. Association between genital schistosomiasis and HIV in rural Zimbabwean women. AIDS 20, 593-600 (2006).

16 Brown M, Mawa PA, Kaleebu P et al. Helminths and HIV infection: epidemiological observations on immunological hypotheses. Parasite Immunol. 28, 613-623 (2006).

17 Bustinduy AL, King CH, Chapter 49: Schistosomiasis. In: Manson's Tropical Diseases 23rd edition. J. Farrar, P. Hotez, T. Junghanss, D. Lalloo, N. White,(Eds). Elsevier, Amsterdam, The Netherlands (2013) (In Press).

18 WHO. Schistosomiasis: number of people treated in 2011. Wkly Epidemiol. Rec. 88, 81-88 (2013).

19 Barry MA, Simon GG, Mistry N et al. Global trends in neglected tropical disease control and elimination: impact on child health. Arch. Dis. Child. 98, 635-641 (2013).

20 Gurarie D, Wang X, Bustinduy AL et al. Modeling the effect of chronic schistosomiasis on childhood development and the potential for catch-up growth with different drug treatment strategies promoted for control of endemic schistosomiasis. Am. J. Trop. Med. Hyg. 84, 773-781 (2011).

.. Showed the chronic impact of schistosomiasis on childhood development as evidenced by retarded growth rates.

21 Ayoya MA, Spiekermann-Brouwer GM, Traore AK et al. Effect on school attendance and performance of iron and multiple micronutrients as adjunct to drug treatment of schistosoma-infected anemic schoolchildren. Food Nutr. Bull. 33, 235-241 (2012).

22 Anderson RM, Truscott JE, Pullan RL et al. How effective is school-based deworming for the community-wide control of soiltransmitted helminths? PLoS Negl. Trop. Dis. 7, (2013).

23 Taylor-Robinson DC, Maayan N, SoaresWeiser K et al. Deworming drugs for soiltransmitted intestinal worms in children: Effects on nutritional indicators, haemoglobin and school performance. Cochrane Database Syst. Rev. (2012).

24 Montresor A, Gabrielli AF, Engels D et al. Has the NTD community neglected evidence-based policy? PLoS Negl. Trop. Dis. 7, (2013).

25 Albonico M, Ame SM, Vercruysse J et al. Comparison of the Kato-Katz thick smear and Mcmaster egg counting techniques for monitoring drug efficacy against soiltransmitted helminths in schoolchildren on Pemba Island, Tanzania.Trans. R. Soc. Trop. Med. Hyg. 106, 199-201 (2012).

26 Albonico M, Rinaldi L, Sciascia S et al. Comparison of three copromicroscopic methods to assess albendazole efficacy against soil-transmitted helminth infections in school-aged children on Pemba Island. Trans. R. Soc. Trop. Med. Hyg. 107, 493-501 (2013).

27 Standley CJ, Adriko M, Alinaitwe M et al. Intestinal schistosomiasis and soiltransmitted helminthiasis in Ugandan schoolchildren: a rapid mapping assessment. Geospat. Health. 4, 39-53 (2009).

28 Standley CJ, Kabatereine NB, Lange CN et al. Molecular epidemiology and phylogeography of Schistosoma mansoni around Lake Victoria. Parasitology. 137, 1937-1949 (2010).

29 Brooker S, Kabatereine NB, Gyapong JO et al. Rapid mapping of schistosomiasis and other neglected tropical diseases in the context of integrated control programmes in Africa. Parasitology. 136, 1707-1718 (2009).
30 Vercruysse J, Behnke JM, Albonico M et al. Assessment of the anthelmintic efficacy of albendazole in school children in seven countries where soil-transmitted helminths are endemic. PLoS Negl. Trop. Dis. 5, (2011).

.. Important synthesis of the present performance of albendazole in several countries in sub-Saharan Africa with advanced methods of fecal egg detection.

31 Olds GR, King C, Hewlett J et al. Doubleblind placebo-controlled study of concurrent administration of albendazole and praziquantel in schoolchildren with schistosomiasis and geohelminths. J. Inf. Dis. 179, 996-1003 (1999).

32 Knopp S, Mohammed KA, Rollinson D et al. Changing patterns of soil-transmitted helminthiases in Zanzibar in the context of national helminth control programs. $A m$. J. Trop. Med. Hyg. 81, 1071-1078 (2009).

33 Stothard JR, French MD, Khamis IS et al. The epidemiology and control of urinary schistosomiasis and soil-transmitted helminthiasis in schoolchildren on Unguja Island, Zanzibar. Trans. R. Soc. Trop. Med. Hyg. 103, 1031-1044 (2009).

34 Keiser J, Utzinger J. Efficacy of current drugs against soil-transmitted helminth infections - systematic review and meta-analysis. JAMA 299, 1937-1948 (2008).

35 Betson M, Sousa-Figueiredo JC, Kabatereine $\mathrm{NB}$ et al. Use of fecal occult blood tests as epidemiologic indicators of morbidity associated with intestinal schistosomiasis during preventive chemotherapy in young children. Am. J. Trop. Med. Hyg. 87, 694-700 (2012).

36 Stothard JR, Rollinson D, Imison E et al. A spot-check of the efficacies of albendazole or levamisole, against soil-transmitted helminthiases in young ungujan children, reveals low frequencies of cure. Ann.Trop. Med. Parasitol. 103, 357-360 (2009).

37 Montresor A, Cure rate is not a valid indicator for assessing drug efficacy and impact of preventive chemotherapy interventions against schistosomiasis and soil-transmitted helminthiasis. Trans. R. Soc. Trop. Med. Hyg. 105, 361-363 (2011).

38 Montresor A, Engels D, Chitsulo L et al. The appropriate indicator should be used to assess treatment failure in STH infections. Am. J. Trop. Med. Hyg. 85, 579-580 (2011).

39 Yajima A, Gabrielli AF, Montresor A et al. Moderate and high endemicity of schistosomiasis is a predictor of the endemicity of soil-transmitted helminthiasis: A systematic review. Trans. R. Soc. Trop. Med. Hyg. 105, 68-73 (2011). 
Operational Guide to Mapping of Schistosomiasis and Soil Transmitted Helminthiasis and Evaluation of Control Programmes. WHO Press, Geneva, Switzerland (2010)

41 Kabatereine NB, Standley CJ, SousaFigueiredo JC et al. Integrated prevalence mapping of schistosomiasis, soil-transmitted helminthiasis and malaria in lakeside and island communities in Lake Victoria, Uganda. Parasit. Vectors. 4, (2011).

42 Huerlimann E, Schur N, Boutsika K et al. Toward an open-access global database for mapping, control, and surveillance of neglected tropical diseases. PLoS Negl. Trop. Dis. 5, (2011).

43 Ekpo UF, Hurlimann E, Schur N et al. Mapping and prediction of schistosomiasis in Nigeria using compiled survey data and bayesian geospatial modelling. Geospat. Health. 7, 355-66 (2013)

44 Dembele M, Bamani S, Dembele R et al. Implementing preventive chemotherapy through an integrated national neglected tropical disease control program in Mali. PLoS Negl. Trop. Dis. 6, (2012).

45 Hodges MH, Magalhaes RJS, Paye J et al. Combined spatial prediction of schistosomiasis and soil-transmitted helminthiasis in Sierra Leone: a tool for integrated disease control. PLoS Negl. Trop. Dis. 6, (2012).

46 Evans D, Mcfarland D, Adamani W et al. Cost-effectiveness of triple drug administration (TDA) with praziquantel, ivermectin and albendazole for the prevention of neglected tropical diseases in Nigeria. Ann. Trop. Med. Parasitol. 105, 537-547 (2011).

47 Humphries D, Sara N, Boakye D et al. The promise and pitfalls of mass drug administration to control intestinal helminth infections. Curr. Opin. Infect. Dis. 25 , 584-589 (2012).

48 Fleming FM, Fenwick A, Tukahebwa EM et al. Process evaluation of schistosomiasis control in Uganda, 2003 to 2006: perceptions, attitudes and constraints of a national programme. Parasitology. 136, 1759-1769 (2009).

49 Montresor A, Stoltzfus RJ, Albonico M et al. Is the exclusion of children under 24 months from anthelmintic treatment justifiable? Trans. R. Soc. Trop. Med. Hyg. 96, 197-199 (2002).

50 Ekpo UF, Oluwole AS, Abe EM et al. Schistosomiasis in infants and pre-schoolaged children in sub-Saharan Africa: implication for control. Parasitology. 139, 835-841 (2012)
51 Seto EYW, Sousa-Figueiredo JC, Betson M et al. Patterns of intestinal schistosomiasis among mothers and young children from Lake Albert, Uganda: water contact and social networks inferred from wearable globa positioning system dataloggers. Geospat. Health. 7, 1-13 (2012).

52 Stothard JR, Sousa-Figueiredo JC, Betson M et al. Schistosomiasis in sub-Saharan African infants and preschool children: Let them now be treated! Trends Parasitol. 29, 197-205 (2013).

- An important paper advocating with evidence the need for treatment of preschool children with praziquantel and regular inclusion into mass drug administration campaigns.

53 Stothard JR, Sousa-Figueiredo JC, Betson M et al. Closing the praziquantel treatment gap: new steps in epidemiological monitoring and control of schistosomiasis in African infants and preschool-aged children. Parasitology 138, 1593-606 (2011).

54 Mutapi F, Rujeni N, Bourke C et al. Schistosoma haematobium treatment in 1-5 year old children: safety and efficacy of the antihelminthic drug praziquantel. PLoS Negl Trop Dis. 5, e1143 (2011).

55 Navaratnam AMD, Sousa-Figueiredo JC, Stothard JR et al. Efficacy of praziquantel syrup versus crushed praziquantel tablets in the treatment of intestinal schistosomiasis in Ugandan preschool children, with observation on compliance and safety. Trans. R. Soc. Trop. Med. Hyg. 106, 400-407 (2012).

56 Navaratnam AM, Mutumba-Nakalembe MJ, Stothard JR et al. Notes on the use of urineCCA dipsticks for detection of intestinal schistosomiasis in preschool children. Trans. R. Soc. Trop. Med. Hyg. 106, 619-622 (2012).

57 Woelfle M, Seerden J-P, De Gooijer J et al. Resolution of praziquantel. PLoS Negl. Trop. Dis. 5, (2011)

58 Dayan AD, Albendazole, mebendazole and praziquantel. Review of non-clinical toxicity and pharmacokinetics. Acta Trop. 86, 141-159 (2003)

59 Doenhoff MJ, Hagan P, Cioli D et al. Praziquantel: its use in control of schistosomiasis in sub-Saharan Africa and current research needs. Parasitology 136, 1825-1835 (2009).

60 Meyer T, Sekljic H, Fuchs S et al. Taste, a new incentive to switch to $(\mathrm{r})$-praziquantel in schistosomiasis treatment. PLoS Negl. Trop. Dis. 3, (2009).
61 Danso-Appiah A, Olliaro PL, Donegan S et al. Drugs for treating Schistosoma mansoni infection. Cochrane Database Syst. Rev. (2013)

- State-of-the-art review on the performance of praziquantel using the Cochrance criteria, it does, however, fail to include all literature reporting on 'cure' and hence is a conservative estimate of drug performance.

62 Keiser J, Ingram K, Utzinger J. Antiparasitic drugs for paediatrics: systematic review, formulations, pharmacokinetics, safety, efficacy and implications for control. Parasitology 138, 1620-1632 (2011).

63 Doenhoff MJ, Cioli D, Utzinger J. Praziquantel: mechanisms of action, resistance and new derivatives for schistosomiasis. Curr. Opin. Infect. Dis. 21, 659-667 (2008).

64 Na-Bangchang K, Kietinun S, Pawa KK et al. Assessments of pharmacokinetic drug interactions and tolerability of albendazole, praziquantel and ivermectin combinations. Trans. R. Soc. Trop. Med. Hyg. 100, 335-345 (2006).

65 Lima RM, Ferreira MA, Ponte TM et al. Enantioselective analysis of praziquantel and trans-4-hydroxypraziquantel in human plasma by chiral lc-ms/ms: application to pharmacokinetics. J. Chromatogr. B Analyt. Technol. Biomed. Life Sci. 877, 3083-3088 (2009).

66 Metwally A, Bennett J, Botros S et al. Impact of drug dosage and brand on bioavailability and efficacy of praziquantel. Pharmacol. Res. 31, 53-59 (1995)

67 Elguiniady MA, Eltouny MA, Abdelbary MA et al. Clinical and pharmacokinetic study of praziquantel in Egyptian schistosomiasis patients with and without liver-cell failure. Am. J. Trop. Med. Hyg. 51, 809-818 (1994).

68 Lima RM, Ferreira MA, de Jesus Ponte Carvalho TM et al. Albendazole-praziquantel interaction in healthy volunteers: kinetic disposition, metabolism and enantioselectivity. Br. J. Clin. Pharmacol. 71, 528-535 (2011).

69 Garcia HH, Lescano AG, Lanchote VL et al. Pharmacokinetics of combined treatment with praziquantel and albendazole in neurocysticercosis. Br. J. Clin. Pharmacol. 72, 77-84 (2011).

70 Parker M, Allen T. Does mass drug administration for the integrated treatment of neglected tropical diseases really work? Assessing evidence for the control of schistosomiasis and soil-transmitted helminths in Uganda. Health Res. Pol. Sys. 9, 3 (2011) 
71 Geary TG. Are new anthelmintics needed to eliminate human helminthiases? Curr. Opin. Infect. Dis. 25, 709-717 (2012).

72 Geary TG, Woo K, Mccarthy JS et al. Unresolved issues in anthelmintic pharmacology for helminthiases of humans. Int. J. Parasitol. 40, 1-13 (2010).

73 Diawara A, Drake LJ, Suswillo RR et al. Assays to detect beta-tubulin codon 200 polymorphism in Trichuris trichiura and Ascaris lumbricoides. PLoS Negl. Trop. Dis. 3(3), e397(2009).

74 Diawara A, Halpenny CM, Churcher TS et al. Association between response to albendazole treatment and beta-tubulin genotype frequencies in soil-transmitted helminths. PLoS Negl. Trop. Dis. 7(5), e2247 (2013).

75 Stothard JR, Sousa-Figueiredo JC, Navaratnam AMD, Advocacy, policies and practicalities of preventive chemotherapy campaigns for sub-Saharan African children with schistosomiasis. Expert Rev. Anti-Inf. Ther. 11, 733-752 (2013).

76 Tchuem-Tuchente LA. Control of soiltransmitted helminths in sub-Saharan Africa: diagnosis, drug efficacy concerns and challenges. Acta Tropica. 120, S4-S11 (2011).

77 Mohammed KA, Haji HJ, Gabrielli A-F et al. Triple co-administration of ivermectin, albendazole and praziquantel in Zanzibar: a safety study. PLoS Negl. Trop. Dis. 2(1), e171 (2008).

- This paper was the first to show the safety of triple therapy of ivermectin, albendazole and praziquantel in a disease endemic setting of sub-Saharan Africa.

78 Namwanje H, Kabatereine N, Olsen A. A randomised controlled clinical trial on the safety of co-administration of albendazole, ivermectin and praziquantel in infected schoolchildren in Uganda. Trans. R. Soc. Trop. Med. Hyg. 105, 181-188 (2011)

79 Namwanje H, Kabatereine NB, Olsen A. The acceptability and safety of praziquantel alone and in combination with mebendazole in the treatment of Schistosoma mansoni and soiltransmitted helminthiasis in children aged 1-4 years in Uganda. Parasitology 138, 1586-1092 (2011).

80 Bartelink IH, Rademaker CM, Schobben AF et al. Guidelines on paediatric dosing on the basis of developmental physiology and pharmacokinetic considerations. Clin. Pharmacokinet. 45, 1077-1097 (2006).

81 Betson M, Sousa-Figueiredo JC, Rowell C et al. Intestinal schistosomiasis in mothers and young children in Uganda: investigation of fieldapplicable markers of bowel morbidity. Am. J. Trop. Med. Hyg. 83, 1048-1055 (2010).

82 Olliaro PL, Vaillant M, Hayes DJ et al. Practical dosing of praziquantel for schistosomiasis in preschool-aged children. Trop. Med. Int. Health. 18, 1085-1089 (2013).

83 Yajima A, Mikhailov A, Mbabazi PS et al. Preventive chemotherapy and transmission control (PCT) databank: a tool for planning, implementation and monitoring of integrated preventive chemotherapy for control of neglected tropical diseases. Trans. R. Soc. Trop. Med. Hyg. 106, 215-222 (2012).

- Provides information on WHO's preventive chemotherapy databank, which is the first point of call for review and assessment of anthelminthic drug coverage by country.

84 WHO. Monitoring drug coverage for preventic chemotherapy. WHO Press, Geneva, Switzerland (2010).

85 Dabo A, Bary B, Kouriba B et al. Factors associated with coverage of praziquantel for schistosomiasis control in the communitydirect intervention (CDI) approach in Mali (West Africa). Infect. Dis. Pov. 2, 11 (2013).

86 Chan JD, Zarowiecki M, Marchant JS. $\mathrm{Ca}\left({ }^{2+}\right)$ channels and praziquantel: A view from the free world. Parasitol. Int. 62(6), 619-628 (2013).

87 Greenberg RM: New approaches for understanding mechanisms of drug resistance in schistosomes. Parasitology 140(12), 1534-1546 (2013)

88 Knopp S, Becker SL, Ingram KJ, Keiser J, Utzinger J: Diagnosis and treatment of schistosomiasis in children in the era of intensified control. Expert Rev. Anti Infect. Ther. 11(11), 1237-1258 (2013).

\section{- Websites}

101 A list of the key commitments at the London Declaration for Neglected Tropical Diseases. www.who.int/neglected_diseases/NTD_ London_Event_Table_Commitments.pdf

102 Up-to-date information of the spatial distribution and cartography of worm infections. www.thiswormyworld.org.

103 Information about ICOSA program as hosted by the Schistosomiasis Contol Initiaitive. www3.imperial.ac.uk/schisto/wherewework/ dfid

104 Informative about ENVISION program as hosted by Research Triangle Institute. www.ntdenvision.org/partner/rti_ international.

105 The WHO preventive chemotherapy databank. www.who.int/neglected_diseases/ preventive_chemotherapy/databank/en/ index.html 